\title{
Influence of hydrology, sediment supply and sediment gradation on river bar morphodynam- ics: application to the Loire River at Bréhémont (France)
}

\author{
Florian Cordier ${ }^{1,2, *}$, Pablo Tassi ${ }^{1,2}$, Nicolas Claude ${ }^{2}$, Alessandra Crosato ${ }^{4}$, Stephane \\ Rodrigues $^{5}$, and Damien Pham Van Bang ${ }^{3}$ \\ ${ }^{1}$ Laboratoire d'Hydraulique Saint-Venant, École des Ponts ParisTech, EDF R\&D, CEREMA (Chatou, \\ France) \\ ${ }^{2}$ Laboratoire National d'Hydraulique et Environnement - EDF R\&D (Chatou, France) \\ ${ }^{3}$ CEREMA (Chatou, France) \\ ${ }^{4}$ IHE Delft (Delft, The Netherlands) \\ ${ }^{5}$ Ecole Polytechnique Universitaire de Tours (Tours, France) \& UMR CNRS 7324 CITERES
}

\begin{abstract}
Rivers inherently show heterogeneous sediment sizes and can also show a strong sediment supply variability in time because of natural episodic events or as a consequence of human activities, which alter the characteristics and dynamics of alluvial bars at the macro-scale. The impact of the combination between sediment size heterogeneity and sediment supply variation, or even with other forcings (i.e. hydrology, channel geometry) remains poorly documented.In this work, a physics-based numerical model is applied on a trained reach of a sandy-gravel bed river to investigate the combination of these parameters on bar morphodynamics. The morphodynamic computations are performed with a two-dimensional depth-averaged hydrodynamic solver, internally coupled to a sediment transport and bed evolution module, which estimate the transport of graded sediment and model bed stratigraphy, respectively. A $1 \mathrm{~km}$ long reach of the Loire River at Bréhémont (France) is selected to conduct the numerical investigations. The interaction between several forcing mechanisms induces highly complex bar morphodynamic processes in this area.A comprehensive set of high-definition data is available, which allows to study the river morphodynamics for a succession of three flooding events and a period of low flows. Based on this model, a variety of scenarios is presented with the aim of exploring the implications of sediment gradation, geometrical and boundary forcing effects on in situ bars morphodynamics.
\end{abstract}

\section{Introduction}

Rivers often present a wavy bed topography due to the presence of periodic bars [1], corresponding to large sediment deposits alternating with deeper areas (pools). These wavy patterns arise from an instability phenomenon of the alluvial bed [2]. A better understanding

\footnotetext{
*e-mail: florian.cordier@edf.fr
} 
of bar processes is important for river engineers and river managers, because bars actively control the riverbed topography and influence bank erosion, with potential harmful consequences for navigation, water intakes and infrastructures [3].

Numerous authors [2] have shown that the formation and the pattern of bars are primarily governed by the width-to-depth ratio of the flow. Grain Size Distribution (GSD) and sediment mobility also influences significantly bar morphodynamics by modifying the characteristics and dynamics of alluvial bars at the macro-scale [4-7]. Sediment supply which can vary significantly in time in rivers [8], is also found to play an significant role on bar morphodynamics [e.g. 9]. Other parameters, such as the hydrology and geometrical forcings (e.g. channel curvature, longitudinal width changes), have also strong implications on sedimentary processes and the resulting bars morphodynamics. Over the years, stability analyses has been proposed to study the initiation conditions for free alternate bars in straight channels under uniform flows [10] and under varying flow conditions [e.g. 11]. Various experimental studies using laboratory flumes focused on the alternate bar response to changing hydrological conditions [e.g. 12]. Geometrical changes in channels induce local areas of erosion or deposition [1], which can trigger the developpement of forced or hybrid bars. Forcing effects due to longitudinal width variations as well as formation of bars driven by channels curvature have been tentatively explained with theory $[13,14]$, laboratory experiments $[15,16]$, field investigations $[3,17]$ and numerical modelling $[14,18,19]$. Although our actual understanding and the modelling of the impact of sediment grading on bar morphodynamics remains limited [20], recent research works [5, 7] have shown the relationship between graded sediment and bars properties, under simple configurations in terms of geometry, hydrology and sediment supply conditions. However, the result of combining graded sediment with other internal and external forcings (sediment supply variation, complex hydrology or channel geometry) remains poorly documented in the literature [21].

The present study is meant to better understand the phenomena induced by the combination of hydrology, sediment supply, channel curvature and graded sediment on bar morphodynamics in natural or trained alluvial riverbeds composed of low mode bars, i.e. alternate and central bars. To reach this goal, a two-dimensional fully-nonlinear model is used to simulate the morphodynamics of a $1 \mathrm{~km}$ long reach of the Loire river at Bréhémont wherein free, hybrid and forced bars coexist [3]. A comprehensive set of high-definition data is available, including in situ flow, bed topography and bedload measurements [22]. The available dataset allows to study the river morphodynamics for three successive flooding events. The morphodynamic numerical model is constructed using the Telemac-Mascaret Modelling System (TMS) (www.opentelemac.org), including the bedload capacity formula of Wilcock and Crowe [23] for graded sediment transport as well as the active layer model formulated by Hirano [24] to account for bed evolution. The substrate is decomposed in several sediment storage layers (i.e. bookkeeping layer model) [25] to model bed stratigraphy. Based on this model, a variety of scenarios are proposed to study the bar morphodynamics in response to the various forcing mechanisms.

\section{Materials and methods}

\subsection{Mathematical and numerical model}

The hydrodynamic module is based on the solution of the shallow-water equations [26]:

$$
\left\{\begin{array}{l}
\partial_{t} h+\vec{u} \cdot \nabla(h)+h \nabla \cdot(\vec{u})=0 \\
\partial_{t} u+\vec{u} \cdot \nabla(u)=-g \partial_{x} z_{f}-g S_{f, x}+h^{-1} \nabla \cdot\left(h v_{t} \nabla u\right) \\
\partial_{t} v+\vec{u} \cdot \nabla(v)=-g \partial_{y} z_{f}-g S_{f, y}+h^{-1} \nabla \cdot\left(h v_{t} \nabla v\right)
\end{array}\right.
$$


where $t[\mathrm{~s}]$ is the time, $\partial_{t}=\partial / \partial_{t}, \nabla=\left(\partial_{x}, \partial_{y}\right)$ is the gradient vector field, $g=9.81 \mathrm{~m} / \mathrm{s}^{2}$ is the acceleration of gravity, $h[\mathrm{~m}]$ is the water depth, $z_{f}=z_{b}+h[\mathrm{~m}]$ the free surface elevation above datum, $z_{b}[\mathrm{~m}]$ the elevation of the bed topography, $\vec{u}=(u, v)[\mathrm{m} / \mathrm{s}]$ the depth-averaged flow velocity vector with $u$ (resp. $v$ ) [m/s] the component along the Cartesian $x$-axis (resp. $y$-axis), with $|\vec{u}|[\mathrm{m} / \mathrm{s}]$ the module of $\vec{u}, S_{f, x}$ (resp. $S_{f, y}$ ) corresponds to the components of the friction law $\overrightarrow{S_{f}}[-]$ along the Cartesian $x$-axis (resp. $y$-axis), and $v_{t}\left[\mathrm{~m}^{2} / \mathrm{s}\right]$ is the turbulent eddy viscosity term. The friction law of Chézy is given as follows:

$$
\overrightarrow{S_{f}}=\left(S_{f, x}, S_{f, y}\right)=\frac{\vec{u}|\vec{u}|}{C^{2} h}
$$

where $C\left[\mathrm{~m}^{1 / 2} / \mathrm{s}\right]$ corresponds to the Chézy friction coefficient. Nikuradse's [27] formula is used to calculate the equivalent friction coefficient of Chézy $C_{f}=g / C^{2}[-]$ as a function of the equivalent roughness height of the bed denoted $k_{s}[\mathrm{~m}]$ :

$$
C_{f}=2\left[\log \left(\frac{30 h}{e \kappa k_{s}}\right)\right]^{-2},
$$

where $\kappa$ is the von Kármán coefficient $(=0.40)$ and $e$ is the base of the natural logarithm.

The morphodynamic module is based on the solution of the Exner equation [28], where in case of non-uniform sediment, the equation is applied to every size fraction of sediment in which the mixture is subdivided. The sediment mixture is discretized into sediment fractions, where the representative diameter of the $i^{t h}$ size fraction of sediment denoted $d_{i}[\mathrm{~m}]$ is given. The bedload transport capacity formula and the mass conservation equation are applied for each separate size fraction. The solution for sediment mass conservation is based on Hirano's [24] mathematical concept, where the bed is decomposed into a homogeneous top layer, called active layer and an unchanging homogeneous substrate. The sediment mass continuity equation is given as follows [e.g. 29]:

$$
L_{a} \partial_{t} F_{a, i}+\left[F_{a, i}-\mathcal{F}_{a: 1, i}\right] \partial_{t} L_{a}=\frac{1}{\epsilon_{0}}\left[\mathcal{F}_{a: 1, i} \nabla \cdot \overrightarrow{q_{b}}-\nabla \cdot q_{b, i}\right]
$$

where $L_{a}[\mathrm{~m}]$ corresponds to the active layer thickness, $F_{a, i}$ is the volume fraction content of the $i^{\text {th }}$ size fraction in the active layer and $\mathcal{F}_{a: 1, i}$ is the volume fraction content of the $i^{\text {th }}$ size fraction in the interface separating the active layer and the substrate, $\overrightarrow{q_{b}}$ $\left[\mathrm{m}^{2} / \mathrm{s}\right]$ corresponds to the total volumetric bedload solid discharge per unit of width without pores, $\overrightarrow{q_{b, i}}=q_{b, i}\left(\cos \alpha_{i}, \sin \alpha_{i}\right)\left[\mathrm{m}^{2} / \mathrm{s}\right.$ ] corresponds to the fractional volumetric bedload solid discharge per unit of width without pores of the $i^{t h}$ size fraction, $\epsilon_{0}=\left(1-P_{0}\right)$ with $P_{0}$ the bed porosity, and $\alpha_{i}$ the angle between the direction of bedload transport of the $i^{t h}$ size fraction and the $x$-axis. In the current model, stratigraphy is obtained by discretizing the substrate into several sub-layers [25], where $F_{k, i}$ is the fraction volume content of the $i^{\text {th }}$ size fraction in the $k^{\text {th }}$ sub-layer.

The magnitude of transport rate of the $i^{t h}$ size fraction without gravitational effects $q_{b 0, i}=$ $\left|q_{b 0, i}\right|\left[\mathrm{m}^{2} / \mathrm{s}\right]$ is estimated using the bedload capacity formula of Wilcock and Crowe [23] hereafter called WC-2003:

$$
W_{i}^{*}=f\left(\tau_{b} / \tau_{r, i}\right)=\frac{\Delta_{s} g q_{b 0, i}}{F_{a, i} u_{*}^{3}},
$$

where $W_{i}^{*}[-]$ corresponds to the dimensionless transport rate for the $i^{\text {th }}$ size fraction of sediment, $\Delta_{s}=\frac{\rho_{s}}{\rho}-1[-]$ is the relative submerged sediment density, with $\rho\left[\mathrm{kg} / \mathrm{m}^{3}\right]$ the water density and $\rho_{s}$ the sediment density $\left[\mathrm{kg} / \mathrm{m}^{3}\right], \tau_{b}[\mathrm{~Pa}]$ is the bed shear stress, $\tau_{r, i}[\mathrm{~Pa}]$ the reference shear stress of the $i^{t h}$ size fraction and $u_{*}=\sqrt{\tau_{b} / \rho}[\mathrm{m} / \mathrm{s}]$ the shear velocity. More 
information about the transport function and the hiding-exposure function of WC-2003 are available in [23]. The bedload magnitude is corrected with the formula proposed by Koch and Flokstra [30]:

$$
q_{b, i}=q_{b 0, i}\left(1-\beta_{1} \partial_{s} z_{b}\right)=q_{b 0, i}\left[1-\beta_{1}\left(\partial_{x} z_{b} \cos \delta+\partial_{y} z_{b} \sin \delta\right)\right],
$$

where $\beta_{1}$ is an empirical coefficient accounting for the streamwise bed slope effect, $\delta$ is the angle between the current and the $x$-axis direction, and $s$ the coordinate along the current direction. The correction of bedload direction is given by the relation of Bendegom [31]:

$$
\tan \alpha_{i}=\frac{\sin \delta-T_{i} \partial_{y} z_{b}}{\cos \delta-T_{i} \partial_{x} z_{b}},
$$

where $\alpha_{i}$ is the angle between the sediment transport vector of the $i^{\text {th }}$ size fraction of sediment and $x$-axis direction which will deviate from the bed shear stress vector due to gravity effects, and where the coefficient $T_{i}$ is calculated as follows [32]:

$$
T_{i}=\left(\beta_{2} \sqrt{\tau_{b, i}^{*}}\right)^{-1},
$$

where $\tau_{b, i}^{*}=\frac{\tau_{b}}{\left(\rho_{s}-\rho\right) g d_{i}}$ is the bed shear stress adimensionnalized by the $i^{\text {th }}$ size fraction of sediment (i.e. Shields parameter) and $\beta_{2}$ is an empirical coefficient used as a calibration parameter.

The total shear stress $\tau=0.5 \rho C_{f}\left(u^{2}+v^{2}\right)[\mathrm{Pa}]$ is calculated from the depth averaged flow velocity field, where $C_{f}$ is equal to the sum of skin friction and bedform drag. The bed shear stress is determined as follows:

$$
\tau_{b}=\mu \tau,
$$

where $\mu=C_{f}^{\prime} / C_{f}$ is the friction factor and $C_{f}^{\prime}$ is only due to skin friction and is the only component acting on bedload [33]. $C_{f}^{\prime}$ is calculated assuming a flat bed by using Nikuradse's formula (Equation 3), where the roughness height $k_{s}^{\prime}[\mathrm{m}]$ is a function of the mean sediment diameter at the bed surface denoted $d_{s, m}[\mathrm{~m}]$ with:

$$
k_{s}^{\prime}=\alpha_{k s} \times d_{s, m}
$$

with $\alpha_{k s}$ a calibration parameter, ranging from 1 to 6.6 [33].

The numerical solution of Equation 1 is based on the finite element method $P_{1}$, where the advective terms are computed with the method of the characteristics. The numerical solution of the sediment transport continuity equation (Equation 4) is performed by a procedure that combines an implicit finite element scheme and an edge-based explicit upwind advection scheme. This procedure assures mass-conservation at machine accuracy, monotonicity of tracers, copes with dry zones and is easily applicable to domain decomposition.

\subsection{Study site and field measurements}

\subsubsection{Study site}

The 1012-km long Loire river is the largest river in France, draining a catchment area of $117,000 \mathrm{~km}^{2}$. The study site (Figure 1) is located in the middle reach of the Loire river at $790 \mathrm{~km}$ downstream from the source, in the vicinity of the village of Bréhémont $\left(47^{\circ} 17^{\prime} 43.31^{\prime \prime} \mathrm{N}, 0^{\circ} 20^{\prime} 33.80^{\prime \prime} \mathrm{E}\right)$. Since the $19^{\text {th }}$ century, the middle Loire has been subject to considerable training works (e.g. embankment, groyne construction, sediment extraction) 
triggering the channelization and the incision of the riverbed, and resulting to a modification of the river morphology and development of vegetation in the riverbed. In this region, the Loire river presents a succession of single to multiple-channel patterns, depicted by the occurence of alternate, transverse, middle and higher mode bars in the main channel. The riverbed also presents secondary channels which are activated and islands which are partially submerged during flooding events.

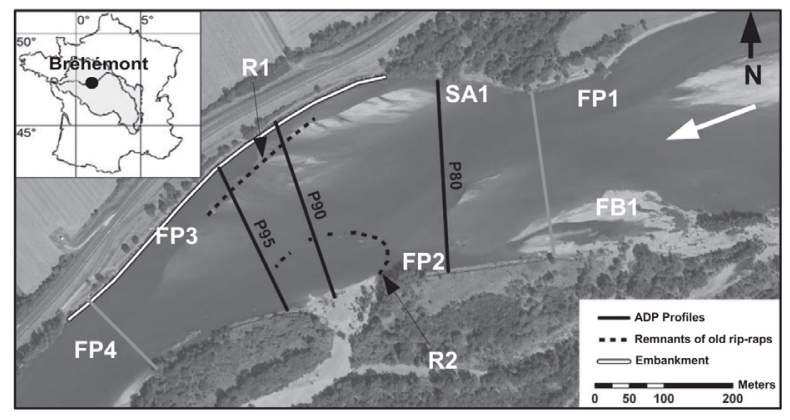

Figure 1. Location of the ADCP profiles, old rip-raps and embankment, and forced bar-pool topography, where the gray lines delimit the area of interest (adapted from Claude et al. [3]). FB = Forced Bar, FP = Forced Pool, R = Rip-rap, SA = Sedimentation Area.

The study reach corresponds to a channel widening followed by a contraction area, wherein alternate and transverse bar configurations have been observed [22]. The presence of embankements on the right riverbank sustaining the main channel curvature, the submerged stretches of rip-rap corresponding to vestiges of ancient bank protection, the longitudinal channel widths variations (from 175 to $300 \mathrm{~m}$ ) and the connexion with a secondary channel (activated for discharges upper than $700 \mathrm{~m}^{3} / \mathrm{s}$ ) generate a permanent geometrical forcing. The latter are associated to forced bar-pool systems and a sedimentation area (Figure 1). The computed width-to-depth ratio in the widening part of the reach ranges between 56 and 159 [22] between June 2010 and January 2011, and the average longitudinal reach slope is equal to 0.3 $\mathrm{m}$ per $\mathrm{km}$. The bed material is mainly composed of a mixture of siliceous sand and gravel and is highly mobile, with a Shields number of approx. 0.10 when the flowrate is equal to 386 $\mathrm{m}^{3} / \mathrm{s}$, with respect to the mean flowrate which is around $430 \mathrm{~m}^{3} / \mathrm{s}$. The sediment diameters $d_{50}$ and $d_{90}$ (corresponding to the $50^{\text {th }}$ and $90^{\text {th }}$ centile of the grain size distribution [m]) are equal to 1.33 and $5.18 \mathrm{~mm}$, respectively. The observed bars dynamics is relatively intense, with bar migration celerity reaching the value of one meter per day, and complex morphodynamics processes are observed with successions of various morphological configurations (transverse and alternate bars) during an hydrologic year.

\subsubsection{Field measurements}

Nineteen field measurements corresponding to the daily monitoring of an annual flood that occured in June $2010\left(1030 \mathrm{~m}^{3} / \mathrm{s}\right.$ peak discharge $)$ and two 2-year return period floods in December $2010\left(1950 \mathrm{~m}^{3} / \mathrm{s}\right.$ and $1760 \mathrm{~m}^{3} / \mathrm{s}$ peak discharge) are used for this study [22] (Figure 2). Daily riverbed topography records of $0.5 \mathrm{~m}$ resolution using multibeam echosoundings are available, as well as longitudinal water free surface profiles. The spatial distribution of velocities has been monitored on three cross-sections (namely P80, P90 and P95, Figure 1) using an ADCP (Acoustic Doppler Current Profiler). Claude et al. [3] estimated bedload transport rates by means of a BTMA (= Bed load TransportMeter Arnhem), from dunes properties and using Meyer-Peter and Müller and Van Rijn [33] bedload transport capacity formulas. 


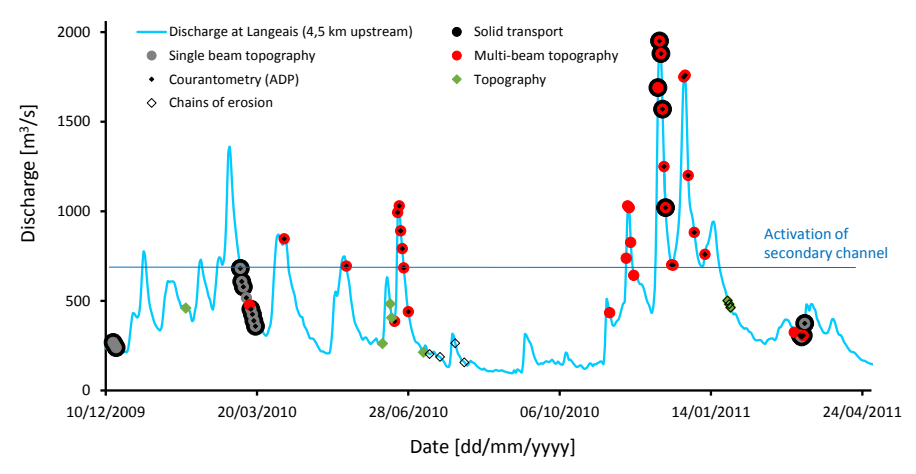

Figure 2. Main field measurements in the site of Bréhémont (Middle Loire river) for the period 2009-2011 (adapted from Claude et al. [22]).

\section{Numerical model setup and calibration}

\subsection{Numerical model setup}

Depending on the considered scenario, the boundary conditions of the hydrodynamic model correspond to an upstream flow discharge and a downstream free surface profile ranging in $[400 ; 1950] \mathrm{m}^{3} / \mathrm{s}$ and in $[32.1 ; 35.2] \mathrm{m}$, respectively. A sediment-feed or a sediment recirculation (periodic condition) is simulated according to the modelled scenario. The upstream and downstream model boundaries have been extended by $2 \mathrm{~km}$ by means of rectilinear reaches of regular slope equal to $i_{0}=0.0003$, in order to allow upstream flow stabilization and lessen the backwater effects in the area of interest due to the imposition of the free surface downstream. The model uses an unstructured computational mesh composed of triangular elements, with typical length equal to $15 \mathrm{~m}$ in the upstream and downstream parts of the domain. Mesh density reduces progressively up to $5 \mathrm{~m}$ in the area of interest and in the secondary channels. The computational time step is fixed to $\Delta t=0.5 \mathrm{~s}$ in order to keep a Courant number below 0.25 . Mesh and time convergence analyses are conducted to ensure numerical stability and to capture local sedimentary processes. For all simulations, $v_{t}=10^{-2} \mathrm{~m}^{2} / \mathrm{s}, \rho=1000 \mathrm{~kg} / \mathrm{m}^{3}$, $\Delta_{s}=1.65$ and $P_{0}=0.40$. In order to model stratigraphy, the bed is discretized from five to twenty vertical sediment storage layers of equal thickness excepted from the deepest layer.

\subsection{Numerical model calibration}

The hydrodynamic model is firstly calibrated on 10 permanent hydrological scenarios (three in June and 7 in December) using $k_{s} \in[0.05-0.50] \mathrm{m}$, with updating the bed topography for each scenario and calibrating on water levels and velocity measurements. The averaged value of the calibrated $k_{s}=0.178 \mathrm{~m}$ is used for the next simulations. Then, the hydro-sedimentary model is calibrated using bedload measurements recorded during these 10 scenarios. Validation of the morphodynamic model is then performed by comparing the computed bar morphodynamic evolution with the one observed in the field from June until December 2010. Results of calibration show that the morphodynamic model can relevantly captures and reproduces the phenomena of interest, where the computed deposition and erosion areas and amplitudes are close to the in situ observations, when the whole hydrogramm is simulated. This last result suggests that the model can be used for further investigations (Figure 3). 

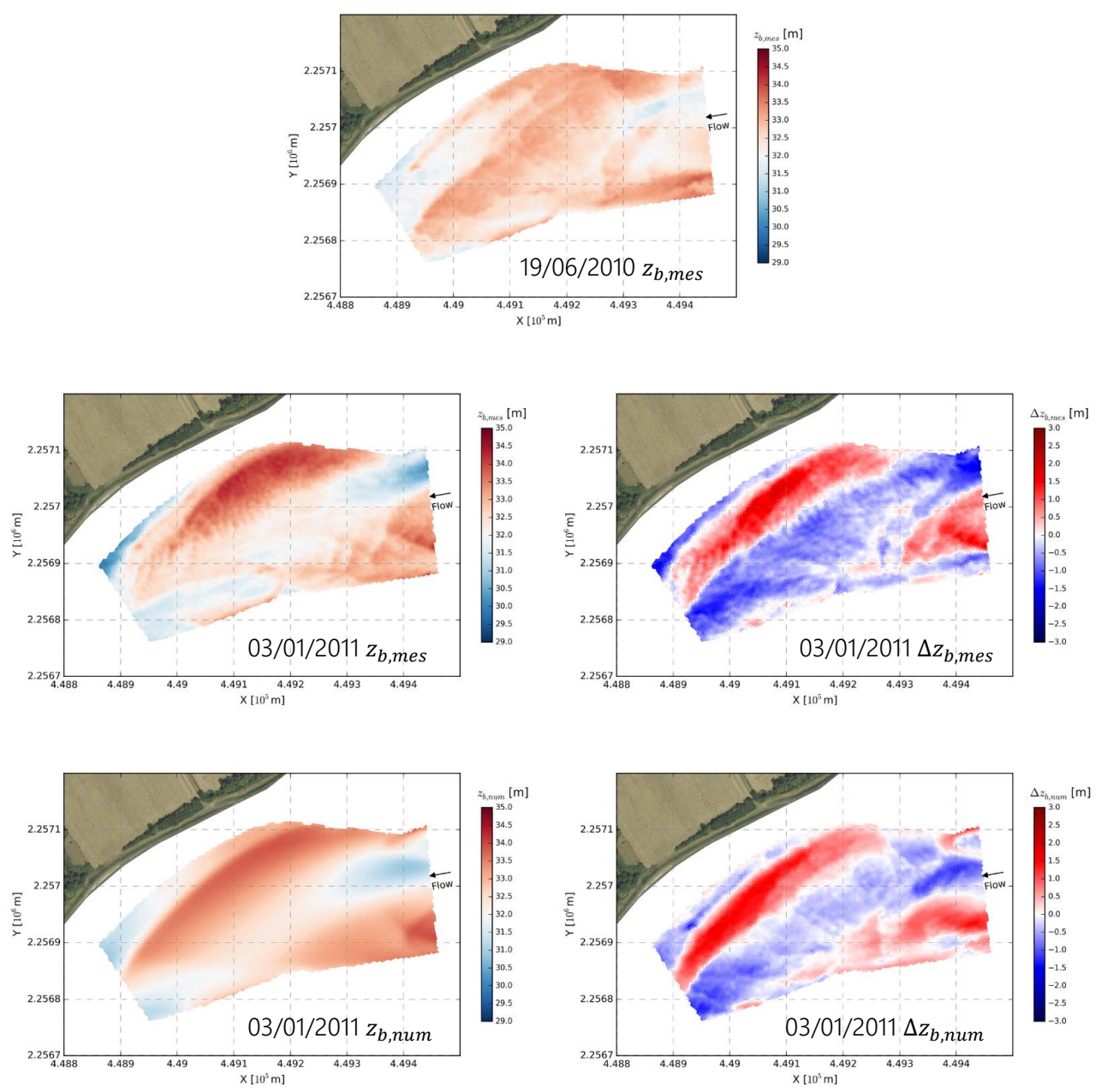

Figure 3. Comparison of bed evolution measured in situ and computed with the numerical model, for the whole hydrological event (from 19/06/2010 to 03/01/2011).

\section{Perspectives}

Based on the calibrated numerical model presented in Section 3.2, a multitude of scenarios will be further investigated. Firstly, the impact of the hydrology and sediment supply on bars morphodynamics will be analyzed. To this goal, different upstream hydraulic (e.g. constant, variable) and morphodynamic (e.g. equilibrium, recirculation) boundary conditions will be prescribed. Secondly, to study the impact of sediment size heterogeneity on bars, a distinct number of representative size fractions of the grain size distribution will be used. The impact of sediment sorting will be estimated by comparing model scenarios with and without sorting of sediment. [7]. Finally, the role played by the submerged rip-raps on the bars morphodynamics could be estimated by comparing the bar topography obtained with and without modelling these local geometrical forcing points. Results from this numerical investigation could help river managers to improve the effects of restoring works and to limit negative environmental impacts due to poorly planned management operations. 


\section{References}

[1] J. Bridge, R. Demicco, Earth surface processes, landforms and sediment deposits (Cambridge University Press, 2008)

[2] A. Crosato, E. Mosselman, Water Resources Research 45, 1 (2009)

[3] N. Claude, S. Rodrigues, V. Bustillo, J.G. Bréhéret, P. Tassi, P. Jugé, Water Resources Research 50, 2850 (2014)

[4] S. Lanzoni, Water Resources Research 36, 3351 (2000)

[5] P.A. Nelson, R.R. McDonald, J.M. Nelson, W.E. Dietrich, Journal of Geophysical Research: Earth Surface 120, 1708 (2015)

[6] U. Singh, A. Crosato, S. Giri, M. Hicks, Advances in Water Resources 104, 127 (2017)

[7] F. Cordier, P. Tassi, N. Claude, A. Crosato, S. Rodrigues, D. Pham Van Bang, Water Resources Research submitted, 1 (2017)

[8] J. Mossa, Geomorphology 252, 112 (2016), the Natural and Human Structuring of Rivers and other Geomorphic Systems: A Special Issue in Honor of William L. Graf

[9] C.J.P. Podolak, P.R. Wilcock, Earth Surface Processes and Landforms 38, 1748 (2013)

[10] B. Federici, G. Seminara, Journal of Fluid Mechanics 487, 125 (2003)

[11] P. Hall, Journal of Fluid mechanics 499, 49 (2004)

[12] Ikeda, Journal of Hydraulic Engineering 110, 371 (1984)

[13] S. Zen, G. Zolezzi, M. Tubino, Advances in Geosciences 39, 27 (2014)

[14] A. Crosato, Analysis and modelling of river meandering (TU Delft, 2008)

[15] F.C. Wu, T.H. Yeh, Journal of Geophysical Research: Earth Surface 110, 1 (2005)

[16] N. Struiksma, K. Olesen, C. Flokstra, H. De Vriend, Journal of Hydraulic Research 23, 57 (1985)

[17] R. Luchi, J. Hooke, G. Zolezzi, W. Bertoldi, Geomorphology 119, 1 (2010)

[18] G. Duró, A. Crosato, P. Tassi, Advances in Water Resources 93, 21 (2016)

[19] P.A. Nelson, A.K. Brew, J.A. Morgan, Water Resources Research 51, 5717 (2015)

[20] A. Siviglia, A. Crosato, Advances in Water Resources 90, 1 (2016)

[21] A.R. Bankert, P.A. Nelson, Sedimentology 10.1111/sed.12399, 1 (2017)

[22] N. Claude, Ph.D. thesis, Tours (2012)

[23] P.R. Wilcock, J.C. Crowe, Journal of Hydraulic Engineering 129, 120 (2003)

[24] M. Hirano, Ph.D. thesis, Japanese Society of Civil Engineering (1971)

[25] A. Blom, Water resources research 44, 1 (2008)

[26] C.B. Vreugdenhil, Numerical methods for shallow-water flow, Vol. 13 (Springer Science \& Business Media, 2013)

[27] J. Nikuradse, Laws of flow in rough pipes (NACA, 1950)

[28] F.M. Exner, Zur physik der dünen (Hölder, 1920)

[29] G. Parker, M. Hassan, P. Wilcock, Developments in Earth Surface Processes 11, 241 (2007)

[30] F. Koch, C. Flokstra, Bed Level Computations for Curved Alluvial Channels: Prepared for the 19th IAHR Congress, New Delhi, India, February 1981 (Waterloopkundig Laboratorium, 1980)

[31] L.V. Bendegom, Dutch. English translation: Nat. Res. Council of Canada, Technical Translation 1054, 1963 (1947)

[32] A. Talmon, N. Struiksma, M. Van Mierlo, Journal of Hydraulic Research 33, 495 (1995)

[33] M.H. García, Processes, Measurements, Modeling, and Practice. ASCE Manuals and Reports on Engineering Practice 110, 1 (2008) 